\title{
Embolization of the choroidal artery in the treatment of cerebral arteriovenous malformations
}

\author{
Alaa Elkordy, MD, ${ }^{1,5}$ Hidenori Endo, MD, PhD, ${ }^{2}$ Kenichi Sato, MD, PhD, ${ }^{3}$ Yasushi Matsumoto, MD, ${ }^{3}$ \\ Ryushi Kondo, MD, PhD, ${ }^{4}$ Kuniyasu Niizuma, MD, PhD, ${ }^{1}$ Toshiki Endo, MD, PhD, ${ }^{2}$ \\ Miki Fujimura, MD, PhD, ${ }^{1}$ and Teiji Tominaga, MD, PhD ${ }^{1}$
}

\begin{abstract}
1Department of Neurosurgery, Tohoku University Graduate School of Medicine, Sendai; Departments of ${ }^{2}$ Neurosurgery and ${ }^{3}$ Neuroendovascular Therapy, Kohnan Hospital, Sendai; ' ${ }^{4}$ epartment of Neurosurgery, Kitasato University School of Medicine, Sagamihara, Japan; and ${ }^{5}$ Neuroendovascular Section, Department of Neurology, Faculty of Medicine, Tanta University, Tanta, Egypt
\end{abstract}

OBJECTIVE The anterior and posterior choroidal arteries are often recruited to supply arteriovenous malformations (AVMs) involving important paraventricular structures, such as the basal ganglia, internal capsule, optic radiation, lateral geniculate body, and medial temporal lobe. Endovascular embolization through these arteries is theoretically dangerous because they supply eloquent territories, are of small caliber, and lack collaterals. This study aimed to investigate the safety and efficacy of embolization through these arteries.

METHODS This study retrospectively reviewed 13 patients with cerebral AVMs who underwent endovascular embolization through the choroidal arteries between 2006 and 2014. Embolization was performed as a palliative procedure before open surgery or Gamma Knife radiosurgery. Computed tomography and MRI were performed the day after embolization to assess any surgical complications. The incidence and type of complications and their association with clinical outcomes were analyzed.

RESULTS Decreased blood flow was achieved in all patients after embolization. Postoperative CT detected no hemorrhagic complications. In contrast, postoperative MRI detected that 4 of the 13 patients $(30.7 \%)$ developed infarctions: 3 patients after embolization through the anterior choroidal artery, and 1 patient after embolization through the lateral posterior choroidal artery. Two of the 4 patients in whom embolization was from the cisternal segment of the anterior choroidal artery (proximal to the plexal point) developed symptomatic infarction of the posterior limb of the internal capsule, 1 of whom developed morbidity $(7.7 \%)$. The treatment-related mortality rate was $0 \%$. Additional treatment was performed in 12 patients: open surgery in 9 and Gamma Knife radiosurgery in 3 patients. Complete obliteration was confirmed by angiography at the last follow-up in 10 patients. Recurrent bleeding from the AVMs did not occur in any of the cases during the follow-up period.

CONCLUSIONS Ischemic complications are possible following the embolization of cerebral AVMs through the choroidal artery, even with modern neurointerventional devices and techniques. Although further study is needed, embolization through the choroidal artery may be an appropriate treatment option when the risk of surgery or radiosurgery is considered to outweigh the risk of embolization.

https://thejns.org/doi/abs/10.3171/2016.2.JNS152370

KEY WORDS arteriovenous malformation; embolization; complications; choroidal artery; vascular disorders; interventional neurosurgery

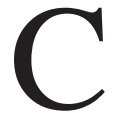
URRENT treatment modalities for cerebral arteriovenous malformations (AVMs) include microsurgical resection, endovascular embolization, and stereotactic radiosurgery. Although these modalities can be used alone, a combination is often necessary to achieve the best treatment results. Each technique can be combined and has its own advantages and disadvantages. Endovascular embolization can be used as a presurgical or preradiosurgical treatment or as a stand-alone curative procedure.

The treatment-related morbidity and mortality of em-

ABBREVIATIONS AChA = anterior choroidal artery; $\mathrm{AVM}=$ arteriovenous malformation; $\mathrm{DWI}=$ diffusion-weighted imaging; $\mathrm{GK}=\mathrm{Gamma}$ Knife; ICA = internal carotid artery; $\mathrm{LPChA}=$ lateral posterior choroidal artery; $\mathrm{NBCA}=\mathrm{N}$-butyl cyanoacrylate; $\mathrm{PChA}=$ posterior choroidal artery.

SUBMITTED October 13, 2015. ACCEPTED February 10, 2016.

INCLUDE WHEN CITING Published online May 6, 2016; DOI: 10.3171/2016.2.JNS152370. 
bolization should be noted. Overall complication rates of AVM embolization have been reported as approximately $5 \%-15 \%, 9,23,25$ whereas a meta-analysis by van Beijnum et al. showed that the total complication rate leading to permanent neurological deficit or death was $6.6 \%$ (range $0 \%-18 \%$ ) after AVM embolization. ${ }^{24}$ In terms of ischemic complications following cerebral AVM embolization, Baharvahdat et al. reported that postoperative ischemia occurred in $6 \%$ of patients ( 827 procedures) ${ }^{1}$

Presurgical embolization of cerebral AVMs is still effective, particularly for deep-seated cerebral AVMs, despite the risk of ischemic complications. Because obliteration of the feeding system tends to be the last step in the surgical correction of deep-seated AVMs supplied by the choroidal arteries, presurgical embolization of these feeders could prove beneficial. However, embolization of the choroidal arteries is challenging and potentially hazardous because they supply crucial structures, including the internal capsule, basal ganglia, medial temporal lobe, optic pathways, cerebral peduncle, and choroid plexus. ${ }^{12}$

In the present study, we retrospectively reviewed patients with cerebral AVMs who underwent endovascular embolization through the choroidal arteries to clarify the risk of complications.

\section{Methods \\ Data Collection}

We retrospectively reviewed the medical charts and imaging records of 116 consecutive patients with cerebral AVMs who were treated by endovascular embolization at Kohnan Hospital between December 2006 and November 2014. Patients were included if they underwent endovascular embolization through the anterior choroidal artery (AChA) and/or the posterior choroidal artery (PChA). All patients were assessed by CT, MRI, and digital subtraction angiography. Preoperative radiological findings were reviewed by experienced neurosurgeons and neuroendovascular interventionists (K.S., R.K., Y.M., and H.E.) to assess the angioarchitecture of the AVMs, including the feeding system, the size of the nidus, the draining system, and the existence of feeder aneurysms, intranidal aneurysms, and/ or venous varix. The Spetzler-Martin grading system was used to establish the AVM grade. ${ }^{20}$ We retrospectively reviewed the clinical and radiological features, which were obtained from both electronic and paper medical records, of the 13 patients included. This study was approved by the institutional review board of Kohnan Hospital.

\section{Treatment Strategy}

Nine patients underwent an embolization procedure in preparation for resection and 3 in preparation for Gamma Knife (GK) radiosurgery. Endovascular embolization through the AChAs or PChAs was performed when flow reduction by embolization of these arterial supplies was considered effective for surgical removal or when it was necessary to obliterate intranidal or feeder aneurysms that were considered likely sites of hemorrhage before GK radiosurgery. Embolization was performed under general anesthesia by a neuroendovascular team in all cases (K.S., R.K., Y.M., and H.E.). Depending on the situation, either $\mathrm{N}$-butyl cyanoacrylate (NBCA) or Onyx (ev3 Neurovas- cular) was used as the embolic agent, which was delivered through a Marathon Flow Directed Micro Catheter (ev3 Neurovascular) and navigated to the choroidal arteries by a CHIKAI 10 or 008 microguidewire (Asahi Intec Co., Ltd.) through a guiding catheter in the internal carotid or vertebral arteries under systemic anticoagulation. The microcatheter tip was advanced distally to select the proper feeders. A schematic illustration of the lateral angiograms is shown in Fig. 1, based on previous literature, to demonstrate the angiographic features of the choroidal arteries. . $^{6,13,22,26}$ In cases with an arterial supply through an AChA, the microcatheter tip was advanced distally to go beyond the angiographic plexal point of the AChA. The catheter position and the degree of the embolic agent reflux were evaluated by the angiography.

\section{Outcome Evaluation}

Both CT and MRI studies were routinely obtained on postoperative Day 1. Any high-density lesions detected by postoperative CT were regarded as hemorrhagic complications, and high-intensity lesions detected by postoperative diffusion-weighted imaging (DWI) were regarded as ischemic complications. A.E., H.E., and K.N. reviewed these postoperative radiological findings. Follow-up digital subtraction angiograms were obtained at 2 weeks and at 6 months after surgery to confirm the disappearance of the AVM. Postoperative neurological status was evaluated by an experienced physical therapist. Each patient's final functional status was evaluated using the modified Rankin Scale (by A.E., H.E., and K.N.).

\section{Results \\ Clinical Backgrounds}

Among the 116 consecutive cases of cerebral AVM treated by endovascular embolization during the study period, we identified 13 patients who were treated by endovascular embolization through the AChA and/or PChA. The patients' characteristics are summarized in Table 1; 9 were female and 4 were male, and the mean age was 32.7 years (range 7-64 years). Hemorrhagic onset was confirmed on CT in all cases. The lesions were located in the frontal lobe in 1 case, the temporal lobe in 5 cases,

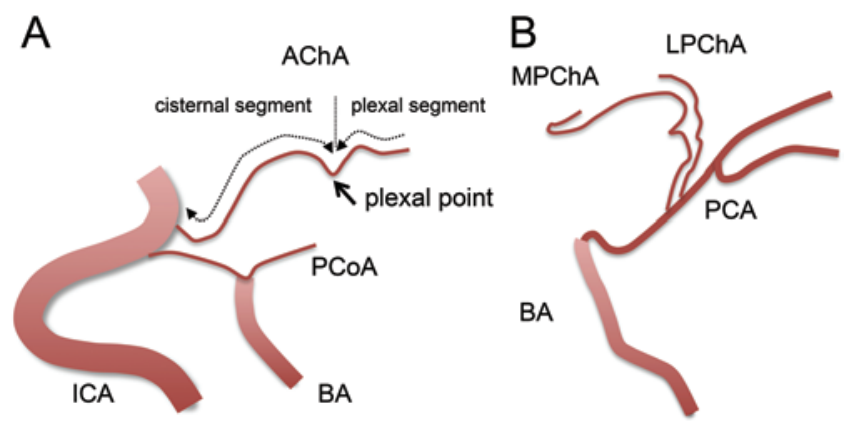

FIG. 1. Schematic illustration of a lateral angiogram showing the angiographic features of the $\mathrm{AChA}(\mathrm{A})$ and $\mathrm{PChA}(\mathrm{B}) . \mathrm{BA}=$ basilar artery; $\mathrm{MPCh} A=$ medial posterior choroidal artery; $\mathrm{PCA}=$ posterior cerebral artery; $\mathrm{PCOA}=$ posterior communicating artery. Figure is available in color online only. 


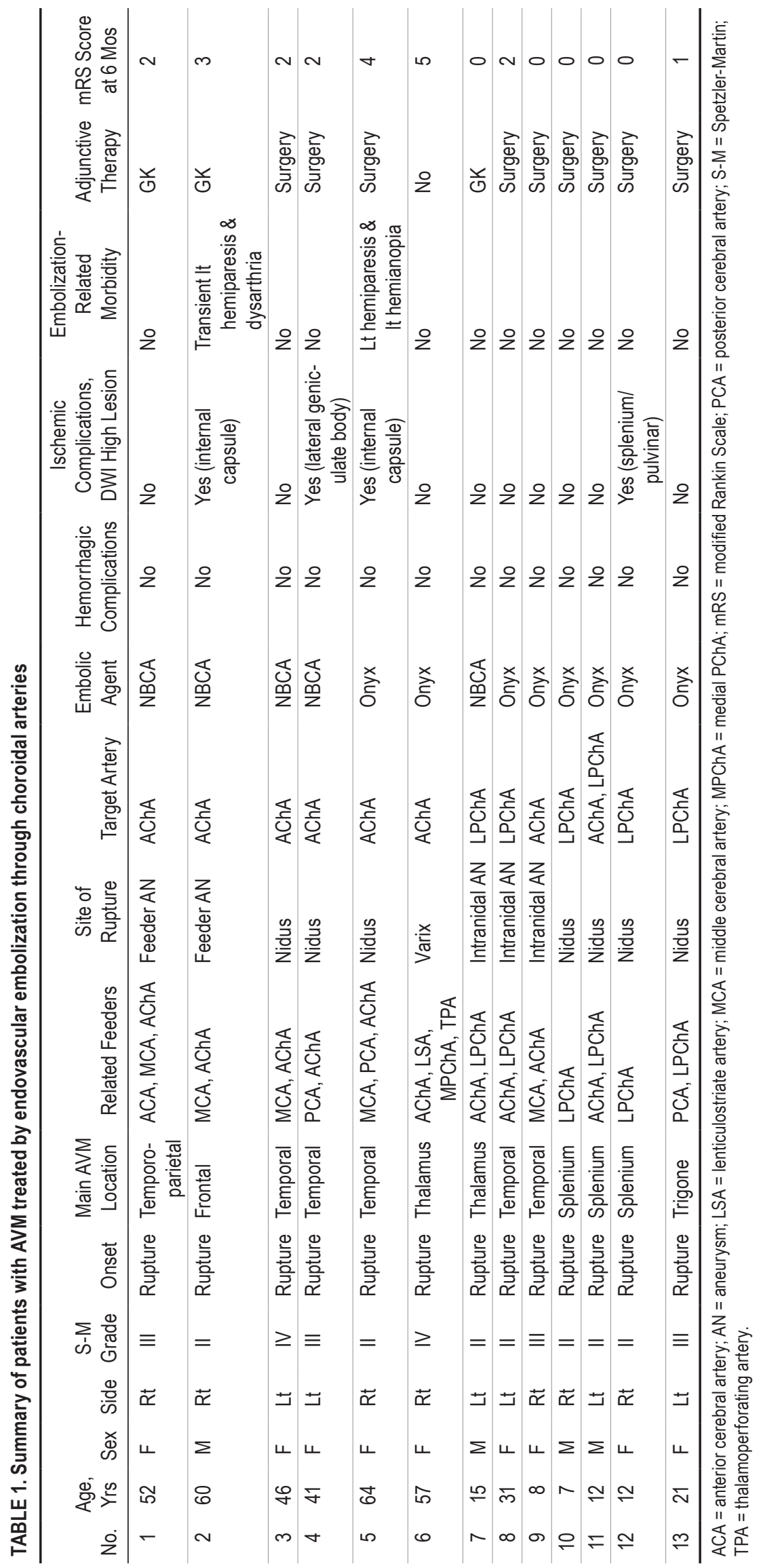




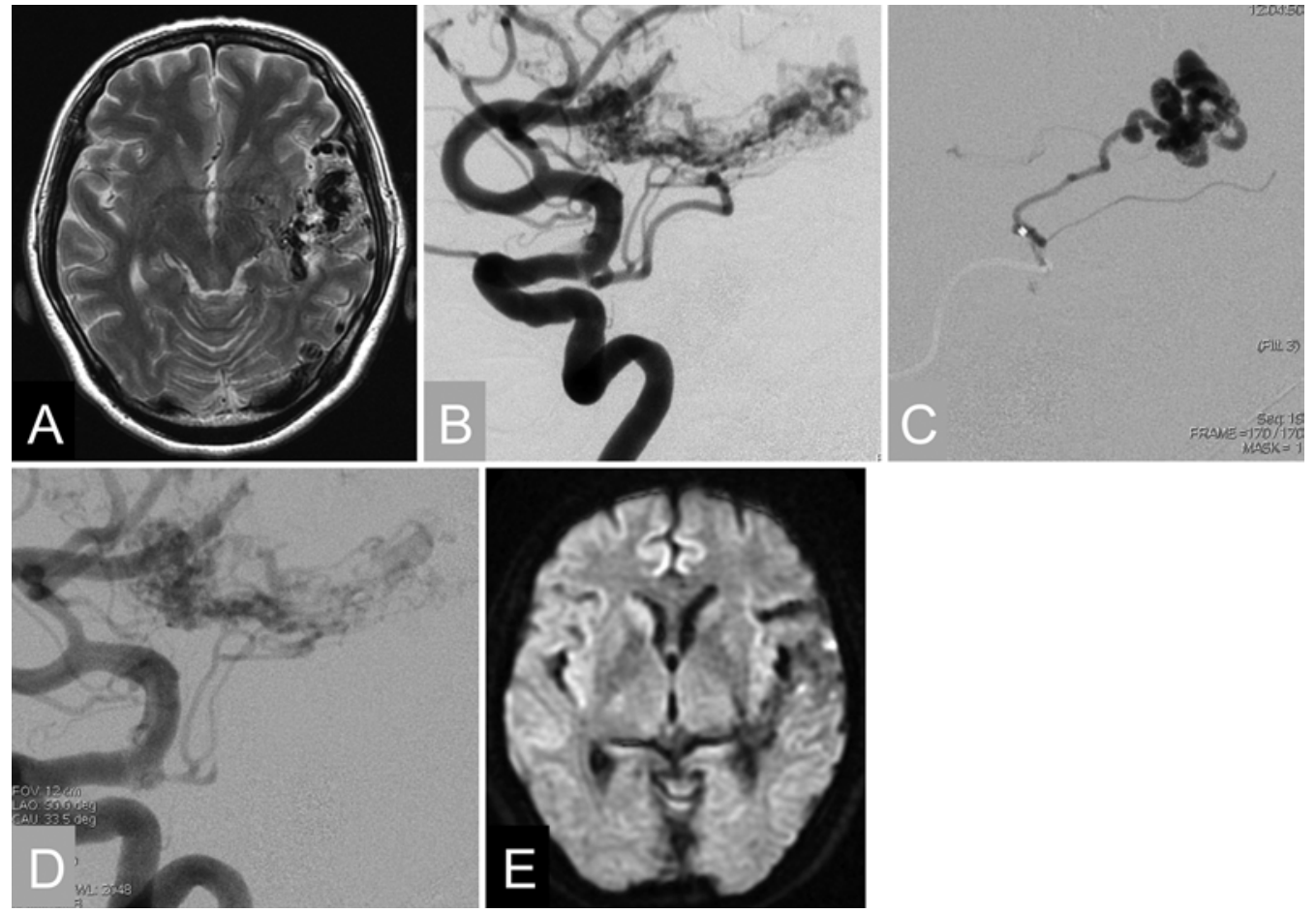

FIG. 2. Case 3. A: A preoperative axial T2-weighted image showing a left medial temporal AVM. B: An angiogram of the left ICA showing a dilated AChA supplying the AVM. C: An angiogram obtained during the injection of NBCA from the microcatheter placed distal to the plexal point. D: An angiogram obtained after the injection of NBCA showing that the posterior part of the nidus was tightly embolized. E: A postoperative DW image showing no ischemic lesions in the AChA territory.

the temporoparietal junction in 1 case, the thalamus in 2 cases, the splenium of the corpus callosum in 3 cases, and the trigone in 1 case. Eloquent brain structures were involved within the nidus in 6 cases (46\%). Spetzler-Martin Grades II, III, and IV were diagnosed in 7, 4, and 2 patients, respectively.

\section{Results of Embolization}

The results of embolization are summarized in Table 1. Of the 13 cases, 7 were embolized through the AChA alone (54\%), 5 through the lateral PChA (LPChA) (38.4\%), and 1 through both arteries (7.6\%). Five patients were embolized using NBCA and 8 using Onyx. Decreased blood flow was achieved in all patients after embolization. Feeder aneurysms on the AChA (Cases 1 and 2) or intranidal aneurysms (Cases 7, 8, and 9), considered to be the rupture site, disappeared after embolization. None of the patients developed hemorrhagic complications on postoperative CT. However, postoperative DWI showed ischemic lesions in 4 cases (30.7\%) (Fig. 2); of these, 3 (Cases 2, 4, and 5) were treated by embolization through the AChA (Fig. 3) and 1 (Case 12) was treated by embolization through the LPChA (Fig. 4).

The catheter position and the degree of embolic-agent reflux in the cases embolized through the AChA are shown in Fig. 5. The microcatheter tip could be advanced distally to the plexal point in 4 of the 8 cases embolized through the AChA (Cases 3, 4, 9, and 11). However, postoperative infarction developed in 2 of the 4 patients in whom embo- lization was from the cisternal segment (proximal to the plexal point) (Cases 2 and 5) and in 1 of the 4 patients in whom embolization was from the plexal segment (distal to the plexal point) (Case 4). Among these, 2 patients (Cases 2 and 5) were embolized from the cisternal segment (proximal to the plexal point), and developed symptomatic infarctions. One patient (Case 2) developed a transient left hemiparesis and dysarthria that improved within 1 week, and the other patient (Case 5) developed a left hemiparesis and left hemianopia that remained at the 6-month followup visit.

\section{Additional Treatment and Clinical Outcomes}

The use of additional treatment methods and the clinical outcomes are summarized in Table 1. Additional treatment was performed in 12 patients, with 9 undergoing open surgery and 3 undergoing GK radiosurgery. The mean blood loss was $540 \mathrm{ml}$ in the 9 cases treated by open surgery. Only 1 patient with a ruptured right trigone AVM (Case 4) needed intraoperative blood transfusion, but the patient was anemic preoperatively. In Case 6, the patient only underwent palliative embolization because she had a diffuse unresectable thalamic AVM with multiple bleeding sites. Complete obliteration was confirmed by cerebral angiography at the 6-month follow-up in 10 patients. A remnant of the nidus was present in 3 cases (Cases 1, 2, and 6) after additional treatment, and a remnant of the nidus was present after GK radiosurgery in 1 patient (Case 1) with a temporoparietal AVM. Gamma Knife radio- 


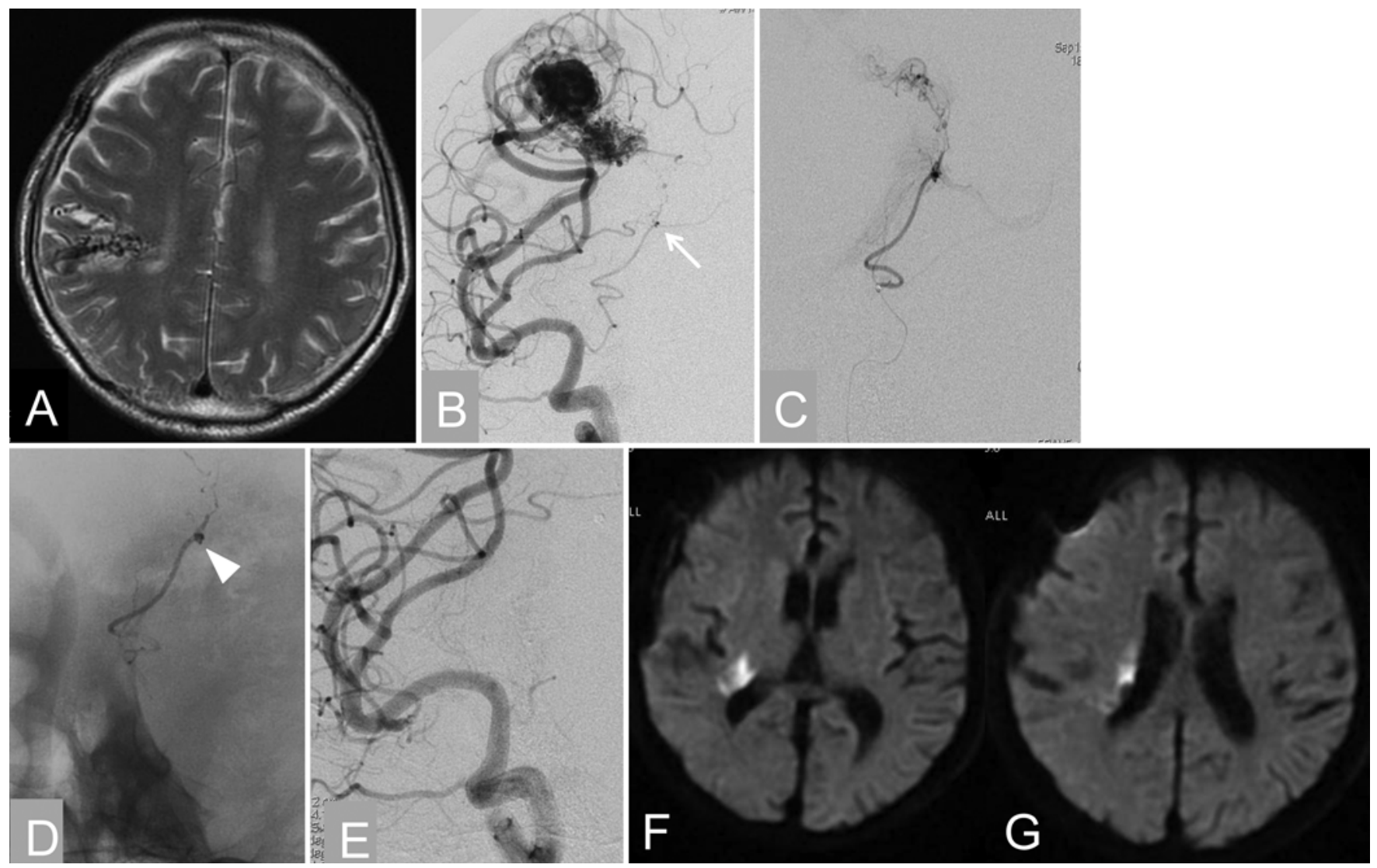

FIG. 3. Case 2. A: A preoperative axial T2-weighted image showing a right frontoparietal AVM extending to the periventricular region. B: An angiogram of the right ICA showing an AVM fed by the right AChA with a small feeder aneurysm (arrow). C: A selective angiogram of the right AChA showing that the microcatheter was placed slightly proximal to the plexal point. D: Nonsubtracted lateral view showing the NBCA cast, which occluded not only the feeder aneurysm (arrowhead), but also the plexal point of the AChA. E: An angiogram obtained after the embolization showing occlusion of the right AChA and disappearance of the aneurysm. F and G: Postoperative axial DW images revealing high-intensity areas near the posterior limb of the internal capsule and the periventricular region.

surgery was recommended for the patient with a frontal AVM (Case 2), but he refused further treatment. Recurrent bleeding from the AVMs did not occur in any cases during the mean follow-up period of 62 months (range 12-105 months).

\section{Discussion}

In this study, we performed embolization of ruptured AVMs through the AChAs and/or LPChAs in 13 patients. Postoperative MRI detected ischemic complication in 4 patients $(30.7 \%)$, of whom 1 had persistent hemiparesis. Treatment-related morbidity and mortality rates were $7.7 \%$ and $0 \%$, respectively, and decreased blood flow was achieved in all patients after embolization. Therefore, in this case series, embolization was a safe and effective procedure. Although the risks of ischemic complications should be considered, embolization of cerebral AVMs through choroidal arteries may be an appropriate treatment before open surgery or GK radiosurgery.

\section{Anatomy of the AChA and PChA, and Related Symptoms}

To achieve safe embolization, it is important to under- stand the anatomical and angiographic features of choroidal arteries. Damage to the AChA during treatment may result in the AChA syndrome, a serious clinical complication that consists of contralateral hemiparesis, hemisensory loss, and homonymous hemianopia. ${ }^{15}$

The AChA can be divided into 2 segments: cisternal and plexal. ${ }^{18}$ The cisternal segment extends from the AChA origin to the choroidal fissure. The terms plexal point or ventral choroidal point have been proposed to describe the point of entry of the AChA into the lateral ventricle at the choroidal fissure. ${ }^{16,26}$ The cisternal segment of the AChA takes a gentle S-shaped course on lateral angiograms. ${ }^{22}$ The plexal point is usually characterized by a steep downward course of a few millimeters, followed by a sharp posterior turn, marking the point of entry on lateral angiograms (Fig. 1). ${ }^{27}$ Principally, the perforating branches of the $\mathrm{AChA}$, which pass through the anterior perforating substance to the globus pallidus and posterior limb of the internal capsule, arise from the cisternal segment and do not receive any significant collateral supply. ${ }^{18}$ Therefore, the catheter tip must be placed beyond the plexal point to avoid serious ischemic complications during AVM embolization through an AChA. ${ }^{3}$ However, in a 

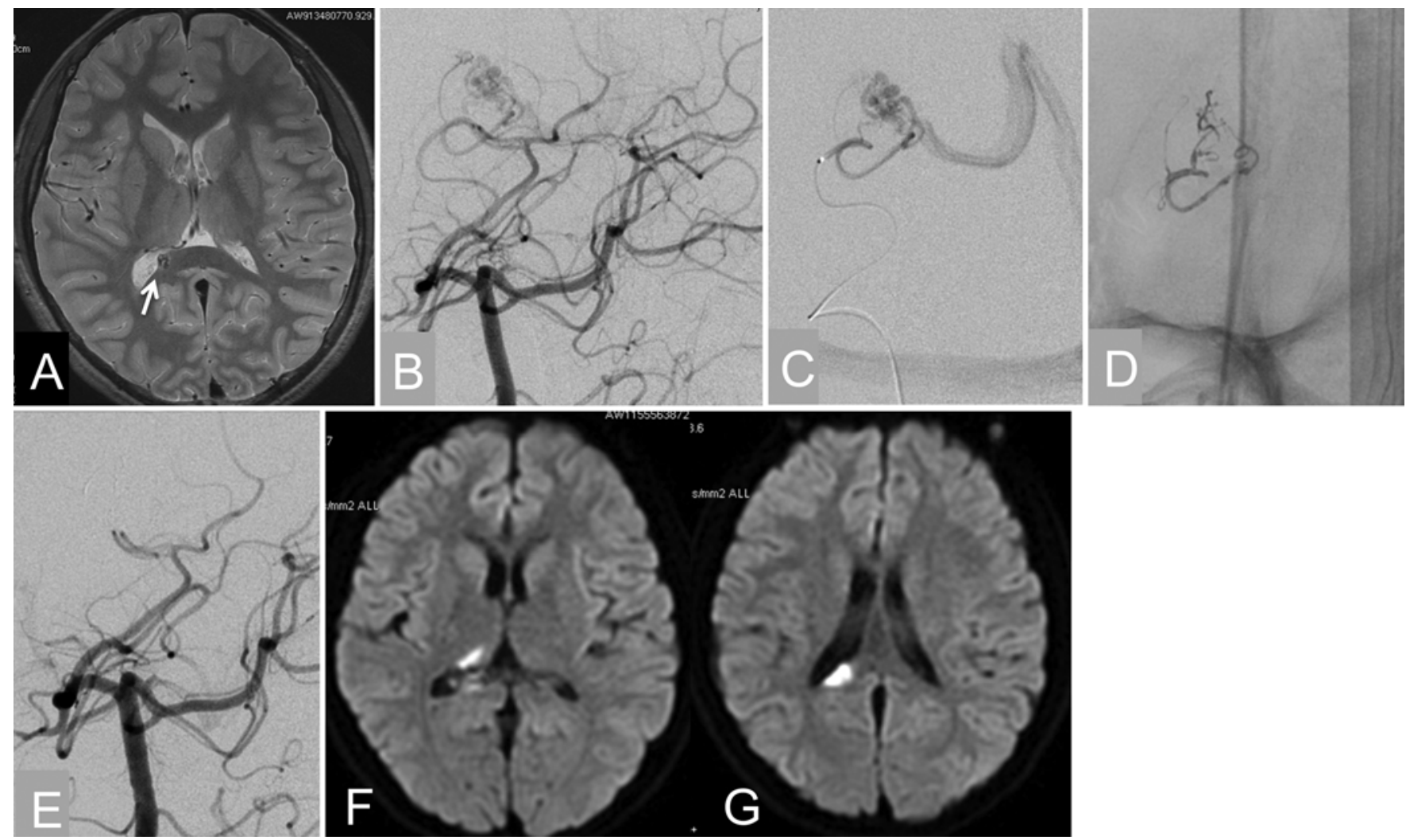

FIG. 4. Case 12. A: A preoperative T2-weighted image showing the small AVM located in the splenium of the corpus callosum (arrow). B: An angiogram of the left vertebral artery showing an AVM fed by the LPChA. C: A selective angiogram of the right LPChA showing an AVM draining into the ventricular vein. D: A nonsubtracted view showing the Onyx cast within the LPChA and the nidus, with minimal reflux of the embolic material. E: An angiogram obtained after the NBCA injection showing the disappearance of the nidus. $\mathrm{F}$ and $\mathrm{G}$ : A postoperative axial DW image revealing the high-intensity areas in the right pulvinar and the splenium of the corpus callosum.

recent cadaveric study, $38 \%$ of the capsulothalamic artery that arises from AChAs originated from the first part of the plexal segment. ${ }^{5}$ This anatomical variation could be an important risk factor during surgery.

Posterior choroidal arteries enter the lateral and third ventricles to supply the choroid plexus and ventricular wall. Among them, the LPChA territory comprises the choroid plexus of the lateral ventricle, the pulvinar, the posterior part of the dorsolateral nucleus, the lateral geniculate body, and the posterior part of the caudate nucleus. ${ }^{17,21,27}$ In some studies, the hippocampus and the mesial temporal lobe were included in the LPChA territory as well. ${ }^{17,21}$ Reports on patients with discrete LPChA infarction are few, and a visual field defect, typically quadrantanopia or hemianopia, is the main symptom. ${ }^{19}$ On the lateral view of cerebral angiograms, the LPChA marks the anterior wall of the atrium of the lateral ventricle and the posterior convexity of the thalamus. ${ }^{6}$ It might be difficult to control ischemic complications after embolization through the LPChA because no angiographic safety point has been reported thus far.

\section{Role of Embolization Through Choroidal Arteries}

Presurgical embolization is the most common indication for endovascular therapy as a part of the comprehen- sive multimodality management of cerebral AVMs. The goals of presurgical embolization are as follows: 1) to eliminate deep arterial pedicles encountered only at the later stages of resection, and 2) to secure AVM-related aneurysms, especially if they are remote from the area of resection. ${ }^{4}$ Surgical access to AChAs can be difficult because of their depth, 7,10 and surgeons might encounter AVMs superficial to choroidal feeding arteries that could hinder surgical manipulation. In this situation, preoperative AChA embolization could be beneficial.

The goals of preradiosurgical embolization are somewhat different, and are as follows: 1) to eliminate highrisk angiographic features that predispose to hemorrhage during the latency period after radiosurgery, and 2) to achieve AVM volume reduction to a size amenable to radiosurgery. ${ }^{8,11}$ Embolization of the choroidal artery could complement radiosurgery by diminishing arteriovenous shunting or by providing palliation through the obliteration of the intranidal aneurysm. ${ }^{3}$

It was difficult to perform curative AVM embolization for the patients included in this study, based on their angioarchitecture. Thus, we decided to perform presurgical or preradiosurgical embolization as an adjunctive management strategy to achieve the goals described above. However, embolization through the choroidal arteries risks ir- 

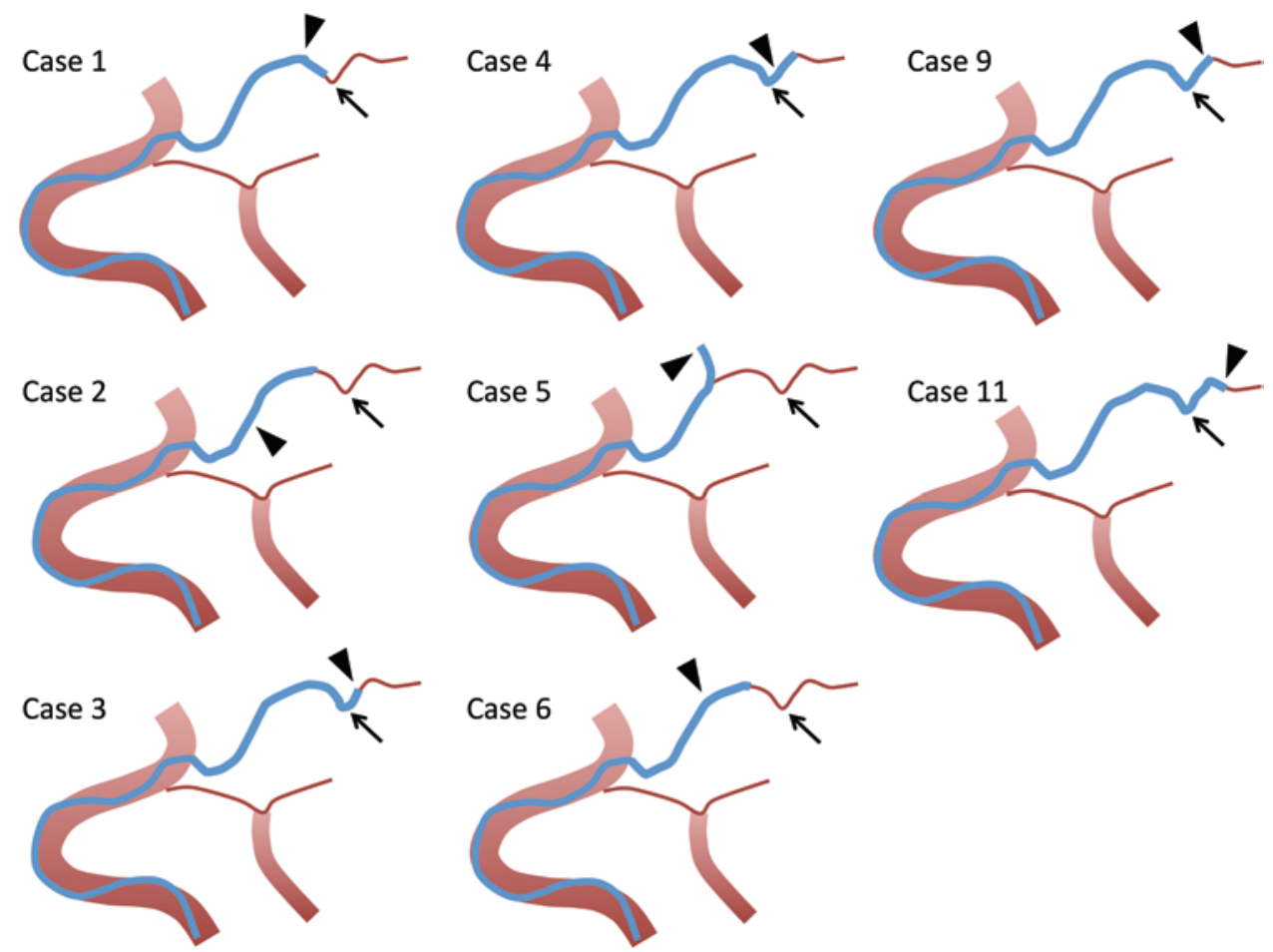

FIG. 5. A schematic illustration of a lateral angiogram showing the microcatheter position and degree of embolic-agent reflux for cases embolized through the AChA. The blue line indicates the position of the microcatheter, the arrow indicates the angiographic plexal point, and the arrowhead indicates the proximal side of the embolic-agent reflux. Figure is available in color online only.

retrievable complications, and should be avoided when the total risk of multimodal treatment strategies outweighs the risk of stand-alone treatment strategies. Before treatment, it is therefore necessary to assess the angioarchitecture of the target AVM in detail, to estimate the potential risk of embolization through the choroidal arteries.

\section{Embolization of Choroidal Arteries in the Treatment of Cerebral AVM}

In our series, angiographically decreased flow to the AVMs was achieved in all patients after embolization through the choroidal arteries, which could lead to shorter surgical procedures and less intraoperative blood loss. To our knowledge, only 2 previous reports have described AVM embolization through choroidal arteries. ${ }^{3,12}$ Dowd et al. described their experience in performing particulate embolization of the AChA in 15 patients. ${ }^{3}$ They experienced 2 hemorrhagic complications due to AChA perforation during the catheterization, in addition to 2 cases of ischemic complications. In that report, 1 patient suffered permanent hemiparesis, which the authors concluded was caused by retrograde thrombosis of the AChA.

Hodes et al. also reported 1 ischemic complication in their series of 6 patients with temporal AVMs embolized through the AChA using cyanoacrylate adhesives..$^{12}$ In that case, catheterization of the AChA was difficult, so they injected the embolic agent at the ostium of the AChA. The patient developed hemiplegia, complete right homonymous hemianopia, and dysphasia postoperatively. ${ }^{12}$ However, these catheterization-related complications have decreased with the advent of modern endovascular techniques and microcatheters. Furthermore, choroidal arteries that feed AVMs are usually dilated enough to be deeply catheterized by the latest microcatheter. The development of smaller, flow-directed catheters, which has led to a decrease in the use of metallic guidewires and balloon catheters, has also allowed more selective catheter placement, and has reduced the risk of vessel perforation or ischemic complications. ${ }^{14}$

We experienced no technical complications during selective microcatheter catheterization of the choroidal arteries in any procedure. However, we could not advance the microcatheter distally to the plexal point of the AChA in 4 of the 8 cases. In 2 of these (Cases 2 and 5), embolization was from the cisternal segment (proximal to the plexal point), and the patients developed postoperative infarctions (1 causing treatment-related morbidity). In Case 2 , the long reflux of embolic material within the cisternal segment of AChA was considered the cause of infarction. In Case 5, although we advanced the microcatheter into the branch arising from the cisternal segment of the AChA (Fig. 5), which was considered the proper feeder by selective angiography, the patient developed infarction of the posterior limb of the internal capsule.

This latter case indicated inadequate branch selection for embolization. However, embolization from the cisternal segment of the AChA does not always result in ischemic complications, suggesting a potential collateral circulation. Thus, it is necessary to minimize the reflux of embolic material to avoid occlusion of these collateral circulations. In Case 4, a small and asymptomatic infarc- 
tion developed at the lateral geniculate body, even though the patient underwent embolization from the distal to the plexal point. This might be explained by anatomical variation of the AChA, with Fujii and Rhoton reporting $24 \%$ of the arterial branch arising from the plexal segment of the AChA supplied the lateral geniculate body. ${ }^{6}$

We speculate that 1 mechanism underlying the ischemic complications in this series was reflux of the embolic agent, the behavior of which varies depending on the agent used. In a recent study by Crowley et al., there was no statistically significant difference in the complication risk following AVM embolization with Onyx and NBCA. ${ }^{2}$ In our series, 2 of 5 cases treated with NBCA and 2 of 8 cases treated with Onyx developed ischemic complications. In addition, there could be a slight difference between the angiographic and the actual behaviors of the embolic materials. We must be aware that not all of the behaviors of the embolic material can be visualized by angiography.

\section{Limitations of the Present Study}

The present study cannot be generalized to other populations because of several limitations. First, this study was conducted in a single center with a small number of patients. Second, we did not include a control group that received stand-alone treatment for comparison. Third, there was an inherent selection bias; we only performed embolization for the patients with hemorrhage and therefore did not include all of the patients with cerebral AVMs supplied by choroidal arteries. Fourth, the retrospective nature may have biased the outcome evaluation, because the treatment team and evaluators partly overlapped. Thus, a prospective study with a larger number of patients treated by embolization through important arteries supplying eloquent areas would provide more relevant evidence about the safety and efficacy of AVM embolization. However, this study does demonstrate that such a study is warranted.

\section{Conclusions}

Ischemic complications are possible following the embolization of cerebral AVMs through the choroidal artery, even with modern neurointerventional devices and techniques. Although further study is needed, embolization through the choroidal artery may be an appropriate treatment option when the risk of surgery or radiosurgery is considered to outweigh the risk of embolization.

\section{Acknowledgments}

We thank Mr. Hiroaki Abe, RPT, MSc, for the assessment of postoperative neurological status. We also thank Enago for the English language review.

\section{References}

1. Baharvahdat H, Blanc R, Termechi R, Pistocchi S, Bartolini B, Redjem H, et al: Hemorrhagic complications after endovascular treatment of cerebral arteriovenous malformations. AJNR Am J Neuroradiol 35:978-983, 2014

2. Crowley RW, Ducruet AF, Kalani MY, Kim LJ, Albuquerque FC, McDougall CG: Neurological morbidity and mortality associated with the endovascular treatment of cerebral arteriovenous malformations before and during the Onyx era. J Neurosurg 122:1492-1497, 2015

3. Dowd CF, Halbach VV, Barnwell SL, Higashida RT,
Hieshima GB: Particulate embolization of the anterior choroidal artery in the treatment of cerebral arteriovenous malformations. AJNR Am J Neuroradiol 12:1055-1061, 1991

4. Ellis JA, Lavine SD: Role of embolization for cerebral arteriovenous malformations. Methodist DeBakey Cardiovasc J 10:234-239, 2014

5. Fernandez-Miranda JC, de Oliveira E, Rubino PA, Wen HT, Rhoton AL Jr: Microvascular anatomy of the medial temporal region: part 1: its application to arteriovenous malformation surgery. Neurosurgery 67:ons237-ons276, 2010

6. Fujii K, Lenkey C, Rhoton AL Jr: Microsurgical anatomy of the choroidal arteries: lateral and third ventricles. $\mathbf{J}$ Neurosurg 52:165-188, 1980

7. Fujita K, Matsumoto S: Anterior choroidal artery arteriovenous malformation. Its clinical manifestations and surgical treatment. Surg Neurol 22:347-352, 1984

8. Gobin YP, Laurent A, Merienne L, Schlienger M, Aymard A, Houdart E, et al: Treatment of brain arteriovenous malformations by embolization and radiosurgery. $\mathbf{J}$ Neurosurg 85:19-28, 1996

9. Hartmann A, Pile-Spellman J, Stapf C, Sciacca RR, Faulstich A, Mohr JP, et al: Risk of endovascular treatment of brain arteriovenous malformations. Stroke 33:1816-1820, 2002

10. Heros RC: Arteriovenous malformations of the medial temporal lobe. Surgical approach and neuroradiological characterization. J Neurosurg 56:44-52, 1982

11. Heros RC: Embolization of arteriovenous malformations. J Neurosurg 100:807-809, 2004

12. Hodes JE, Aymard A, Casasco A, Rüfenacht D, Reizine D, Merland JJ: Embolization of arteriovenous malformations of the temporal lobe via the anterior choroidal artery. AJNR Am J Neuroradiol 12:775-780, 1991

13. Ikeda K, Shoin K, Mohri M, Kijima T, Someya S, Yamashita $\mathrm{J}$ : Surgical indications and microsurgical anatomy of the transchoroidal fissure approach for lesions in and around the ambient cistern. Neurosurgery 50:1114-1120, 2002

14. Ledezma CJ, Hoh BL, Carter BS, Pryor JC, Putman CM, Ogilvy CS: Complications of cerebral arteriovenous malformation embolization: multivariate analysis of predictive factors. Neurosurgery 58:602-611, 2006

15. Masson M, Decroix JP, Henin D, Dairou R, Graveleau P, Cambier J: [Anterior choroidal artery syndrome. Clinical and computed tomography study of 4 cases.] Rev Neurol (Paris) 139:547-552, 1983 (Fr)

16. Morandi X, Brassier G, Darnault P, Mercier P, Scarabin JM, Duval JM: Microsurgical anatomy of the anterior choroidal artery. Surg Radiol Anat 18:275-280, 1996

17. Neau JP, Bogousslavsky J: The syndrome of posterior choroidal artery territory infarction. Ann Neurol 39:779788, 1996

18. Rhoton AL Jr, Fujii K, Fradd B: Microsurgical anatomy of the anterior choroidal artery. Surg Neurol 12:171-187, 1979

19. Saeki N, Shimazaki K, Yamaura A: Isolated infarction in the territory of lateral posterior choroidal arteries. J Neurol Neurosurg Psychiatry 67:413-415, 1999

20. Spetzler RF, Martin NA: A proposed grading system for arteriovenous malformations. J Neurosurg 65:476-483, 1986

21. Takahashi S, Goto K, Fukasawa H, Kawata Y, Uemura K, Yaguchi K: Computed tomography of cerebral infarction along the distribution of the basal perforating arteries. Part II: Thalamic arterial group. Radiology 155:119-130, 1985

22. Takahashi S, Suga T, Kawata Y, Sakamoto K: Anterior choroidal artery: angiographic analysis of variations and anomalies. AJNR Am J Neuroradiol 11:719-729, 1990

23. Taylor CL, Dutton K, Rappard G, Pride GL, Replogle R, Purdy PD, et al: Complications of preoperative embolization of cerebral arteriovenous malformations. J Neurosurg 100:810-812, 2004 
24. van Beijnum J, van der Worp HB, Buis DR, Al-Shahi Salman R, Kappelle LJ, Rinkel GJ, et al: Treatment of brain arteriovenous malformations: a systematic review and metaanalysis. JAMA 306:2011-2019, 2011

25. Weber W, Kis B, Siekmann R, Kuehne D: Endovascular treatment of intracranial arteriovenous malformations with onyx: technical aspects. AJNR Am J Neuroradiol 28:371377, 2007

26. Wiesmann M, Yousry I, Seelos KC, Yousry TA: Identification and anatomic description of the anterior choroidal artery by use of 3D-TOF source and 3D-CISS MR imaging. AJNR Am J Neuroradiol 22:305-310, 2001

27. Zeal AA, Rhoton AL Jr: Microsurgical anatomy of the posterior cerebral artery. J Neurosurg 48:534-559, 1978

\section{Disclosures}

The authors report no conflict of interest concerning the materi- als or methods used in this study or the findings specified in this paper.

\section{Author Contributions}

Conception and design: H Endo, Sato, Matsumoto, Niizuma. Acquisition of data: H Endo, Elkordy, Sato, Matsumoto, Kondo. Analysis and interpretation of data: $\mathrm{H}$ Endo. Drafting the article: Elkordy. Critically revising the article: H Endo, Sato, Fujimura. Reviewed submitted version of manuscript: $\mathrm{H}$ Endo, Kondo, $\mathrm{T}$ Endo, Fujimura. Approved the final version of the manuscript on behalf of all authors: H Endo. Study supervision: Matsumoto, Tominaga.

\section{Correspondence}

Hidenori Endo, Department of Neurosurgery, Kohnan Hospital, 4-20-1 Nagamachi-minami, Taihaku-ku, Sendai, 982-8523, Japan. email: hideendo@gmail.com. 